\title{
Spontaneous rupture of a nonparasitic hepatic cyst associated with peritonitis
}

\author{
PATRICIA SHIPLEY, BSC, BARRY BAyLis, MD, NOEL HERSHFIELD, MD, \\ ROBERT LUI, MD, NORMAN CW WONG, MD
}

P Shipley, B Baylis, N Hershfield, R LUi, NCW Wong. Spontaneous rupture of a nonparasitic hepatic cyst associated with peritonitis. Can J Gastroenterol 1991;5(5):171-173. The first report of a nonparasitic cyst complicated by rupture and peritonitis is given. A 63 -year-old female found to have a nonparasitic hepatic cyst was discharged from hospital when her symptoms of sharp intermittent pains in the right upper quadrant resolved spontaneously. Hours later, she was re-admitted with rupture and peritonitis. After hepatic cystojejunostomy (Roux-en-y) and T-tube placement in the common bile duct, the patient remains asymptomatic two years later.

Key Words: Hepatic cyst, Nonparasitic, peritonitis, Rupture

\section{Rupture spontanée d'un kyste hépatique d'origine non parasitaire et péritonite}

RESUME: On rapporte le premier cas de kyste non parasitaire compliqué d'une rupture et d'une péritonite. Une patiente de 63 ans et chez qui on avait diagnostiqué un kyste hépatique avait pu regagner son domicile quand les douleurs vives et intermittentes qu'elle éprouvait à hauteur du quadrant supéroexterne droit avaient spontanément cessé. Quelques heures plus tard, elle a été de nouveau hospitalisée souffrant d'une rupture de kyste et d'une péritonite. La patiente a subi une cystojéjunostomie (opération de Roux en y) avec pose d'un drain de Kehr dans la voie biliaire principale. Elle est toujours asymptomatique deux ans plus tard.

Departments of Medicine, Medical Biochemistry, and Surgery, University of Calgary, Calgary, Alberta

Correspondence and reprints: Dr Norman CW Wong, Faculty of Medicine, University of Calgary, 3330 Hospital Drive NW, Calgary, Alberta T2N 4NI

Received for publication July 15, 1991. Accepted October 7, 1991
I N MOST INCIDENCES NONPARASITIC hepatic cysts are uncomplicated, but the authors have recently encountered a case associated with spontaneous rupture leading to peritonitis. The occurrence of nonparasitic hepatic cysts is very low, clearly demonstrated by the results of a 15 year retrospective study at the Mayo Clinic in which 10,000 abdominal operations were surveyed and only 15 found to be due to a nonparasitic hepatic cyst $(1,2)$. The finding of a nonparasitic cyst complicated by rupture and peritonitis is extremely rare, thus prompting the authors to summarize their experience in this report.

\section{CASE PRESENTATION}

A 63-year-old female was admitted to the Calgary Foothills General Hospital complaining of sharp intermittent pains in the right upper quadrant of the abdomen with radiation to the right shoulder and arm. Six months previously the patient had experienced episodes of recurrent fever, chills and fatigue. The only significant finding at 

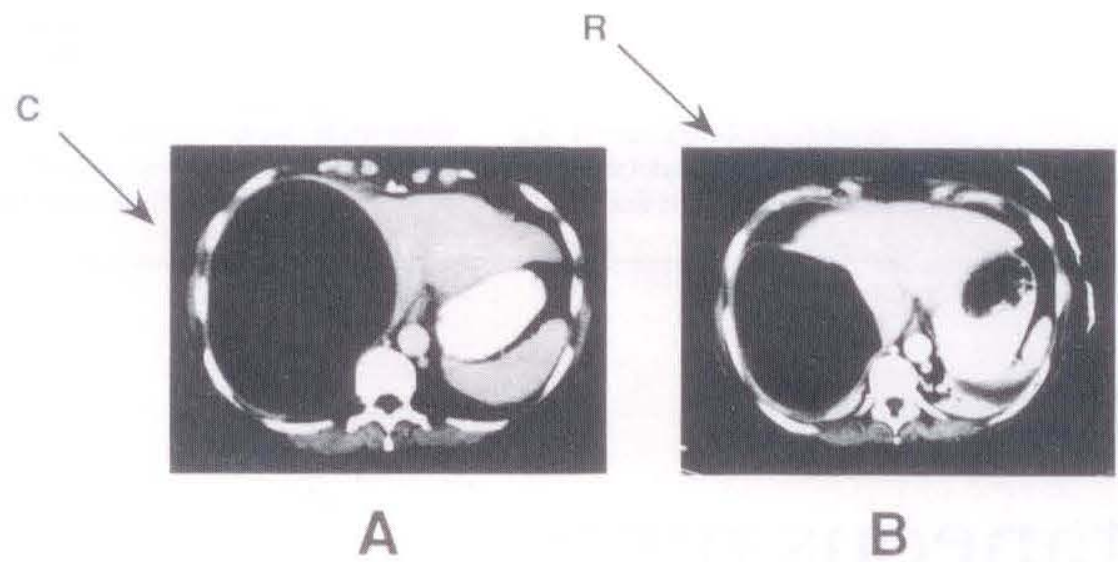

B

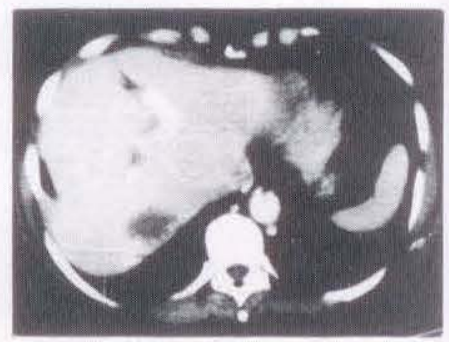

C

Figure 1) Computed tomography scan of a solitary nonparasitic cyst (C) of the liver, before (A) and during rupture (B) of the lesion and after surgical treatment (C). A The lesion (C) in the right lobe of the liver before rupture, B Rupture of the cyst into the subcapsular region. Extravasation of fluid from the cyst into the subcapsular space is indicated by the R. C A subsequent scan performed five months following surgery, demonstrating that the lesion has not recurred

the time of admission was a tender globular mass located in the right upper quadrant of the abdomen, that moved with respiration. Auscultation of the mass failed to reveal a rub or bruit.

Laboratory investigations showed that white blood cell count $\left(5.8 \times 10^{9} / \mathrm{L}\right)$, aspartate aminotransferase $(25 \mathrm{U} / \mathrm{L})$ and total bilirubin $(11 \mu \mathrm{mol} / \mathrm{L})$ were all within normal limits. Potential etiologies for hepatic cyst such as amebiasis and echinococcus were excluded by negative serology. The only positive finding was an ultrasound study showing a homogeneous solitary cyst $\left(13 \times 15 \mathrm{~cm}^{2}\right)$ on the inferior surface of the right lobe of the liver. The location and size of this lesion was confirmed by computed tomography scan (Figure 1A). The course in hospital was unremarkable. The patient's symptoms resolved spontaneously, and the patient was discharged.

Within hours of discharge, a sudden change in the characteristics of the pain prompted the patient to return to hospital. This time, the abdominal pain was severe and generalized. Physical examination on re-admission showed that the patient was in acute distress (blood pressure $140 / 80 \mathrm{mmHg}$, pulse 120 beats/min, and respiratory rate 24/ min). Abdominal examination revealed a distended abdomen and signs of peritonitis. Significant laboratory findings included a white blood cell count of $15.6 \times 10^{9} / \mathrm{L}$ with $87 \%$ polymorphonuclear cells. A flat plate $\mathrm{x}$-ray of the abdomen had the appearance of ground glass, suggesting the presence of fluid in the peritoneal cavity. Repeat computed tomography scan demonstrated that the cyst had ruptured and broken through Glissen's capsule (Figure 1B). Medical management included intravenous fluids and an antibiotic, cefoxitin ( 2 g every $4 \mathrm{~h}$ ).

After the patient's condition had stabilized, she underwent hepatic cystojejunostomy (Roux-en-y) and T-tube placement in the common bile duct. Analysis of fluid from the cyst revealed both blood and bile, but cultures of the fluid were negative. An intraoperative T-tube cholangiogram failed to show communication of the cyst with the biliary tree. Histological reports indicated that the cyst was lined by low columnar epithelial cells of uniform thickness with no evidence of malignancy. The patient's postoperative course was unremarkable. No complications or recurrence were encountered during a brief follow-up period (Figure 1C), and the patient remains asymptomatic two years following the procedure.

\section{DISCUSSION}

In the present report the authors have summarized the events leading up to the diagnosis and management of a nonparasitic cyst of the liver. The histological finding of low columnar epithelial cells indicates that the lesion was a congenital ductal cyst of the liver (2). Congenital hepatic cysts in the absence of polycystic kidney disease are very uncommon (2). The incidence of this disease is highest in elderly females (3). The single feature of this case presentation that sets it apart from others is the spontaneous rupture of the cyst leading to peritonitis.

Solitary congenital hepatic cysts are classified as being either parenchymal or ductal $(4,5)$. Conservative management is usually indicated for asymptomatic solitary parenchymal or ductal cysts, but complications may occur. Parenchymal cysts arise from the tissue of mucous glands or from the teres ligamentum (6). Cysts of this nature give rise to symptoms of abdominal fullness and bile tract obstruction when they become filled with transudative fluid $(3,7-10)$. In contrast, ductal cysts arise from the failure of provisional embryonic bile ducts to undergo involution $(1,5,7,10)$. Despite the absence of communication between ductal cysts and major bile tracts $(1,11)$, hemorrhage and bile leakage into the cyst are known complications $(2,3,10)$.

The literature contains only three documented cases of nonparasitic hepatic cyst that ruptured, none of which were associated with peritonitis 
$(2,10,12)$. The authors have documented the present case as an example that goes against the general belief that rupture of a nonparasitic hepatic cyst is a benign condition. In light of this experience the authors suggest that more aggressive management may be indicated in certain cases. For example, cysts that contain transudates may be

\section{REFERENCES}

1. Sanfelippo P, Bearhs D, Weiland L. Cystic disease of the liver. Ann Surg 1974;179:922-5.

2. Horton R. Giant cyst of the liver complicated by rupture. Br J Surg 1954:41:442-4.

3. Litwin DEM, Taylor BR, Langer B, Greig P. Nonparasitic cysts of the liver. The case for conservative surgical management. Ann Surg 1987;205:45-8.

4. Clinkscales N, Trigg L, Poklepovic J. Obstructive jaundice secondary to benign hepatic cyst. Radiology 1985;154:643.

5. Trinkl W, Sassaris M, Hunter F. Nonsurgical treatment for symptomatic nonparasitic liver cyst. Am J drained with transabdominal aspiration $(4,13,14)$. External drainage is indicated for infected cysts. In contrast, bileor blood-containing cysts can be safely drained by cystojejunostomy. Because hepatic cyst rupture occurs most commonly in the elderly it is essential that early surgical intervention be weighed against the potential outcome describ-

Gastroenterol 1985;80:907-11.

6. Sood S, Watson A. Solitary cyst of the liver presenting as an abdominal emergency. Postgrad Med ] 1974;50:48-50.

7. Flag R, Robinson D. Solitary nonparasitic hepatic cysts. Arch Surg 1967;15:964-73.

8. Henson S, Gray H, Dockerly M. Benign tumors of the liver. Surg Gynecol Obstet 1957;103:607-9.

9. Davis C. Nonparasitic cysts of liver. Am J Surg 1937:35:590-4.

10. Hamlin E. Case records of the Massachusetts General Hospital. N Engl J Med 1951;244:66-70.

11. Edwards J, Eckhauser F, Knol J, Stroder W, Appelman H. Optimizing surgical ed above, as this age group is least capable of tolerating severe illness.

In conclusion, the authors have reported a case of nonparasitic cyst of the liver that ruptured, leading to acute peritonitis. To their knowledge, this is the only reported case in which peritonitis has occurred following rupture of a nonparasitic hepatic cyst.

management of symptomatic solitary hepatic cysts. Am Surg 1987;53:510-4.

12. Akriviadis E A, Steindel H, Ralls P, Redeker A. Spontaneous rupture of nonparasitic cyst of the liver. Gastroenterology 1989:97:213-5.

13. Cappell MS. Obstructive jaundice from benign, nonparasitic hepatic cyst: Identification of risk factors and percutaneous aspiration for diagnosis and treatment. Am J Gastroenterol 1988;83:93-6.

14. Roemer CE, Ferrucci JT, Mueller PR, Simeone JF, vanSonnenberg E, Wiftenberg J. Hepatic cyst: Diagnosis and therapy by sonographic needle aspiration. Am J Roentgenol 1981;136:1065-70 


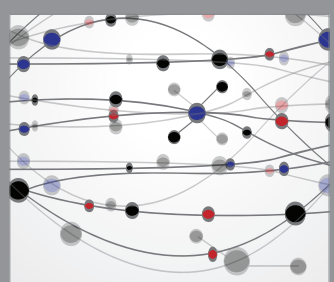

The Scientific World Journal
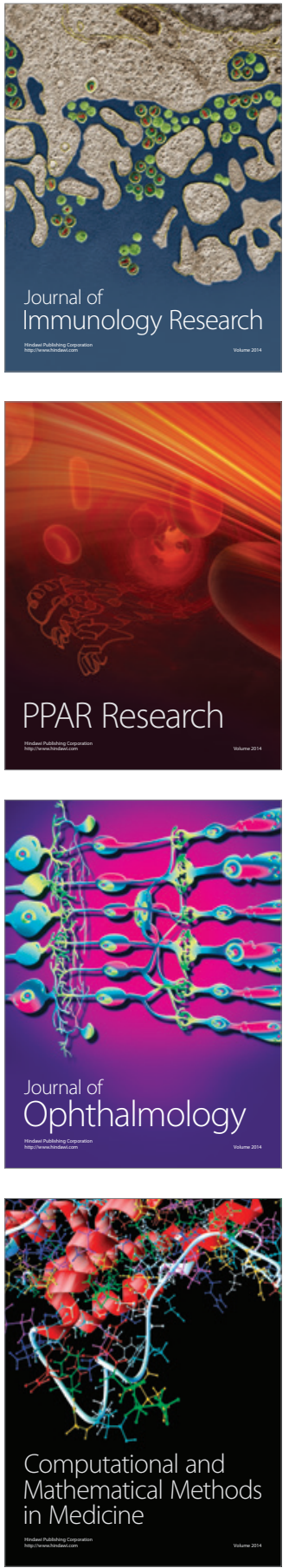

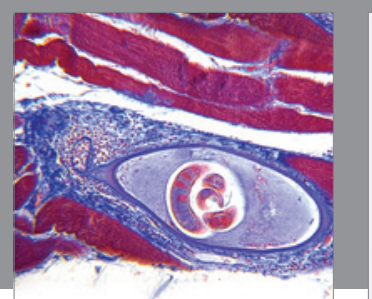

Gastroenterology Research and Practice

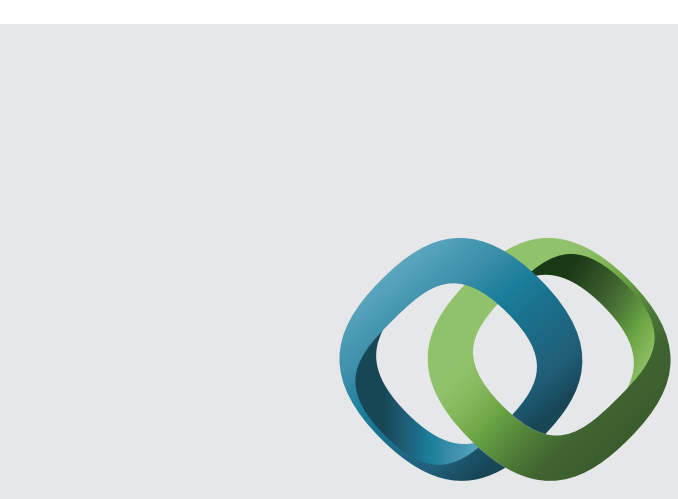

\section{Hindawi}

Submit your manuscripts at

http://www.hindawi.com
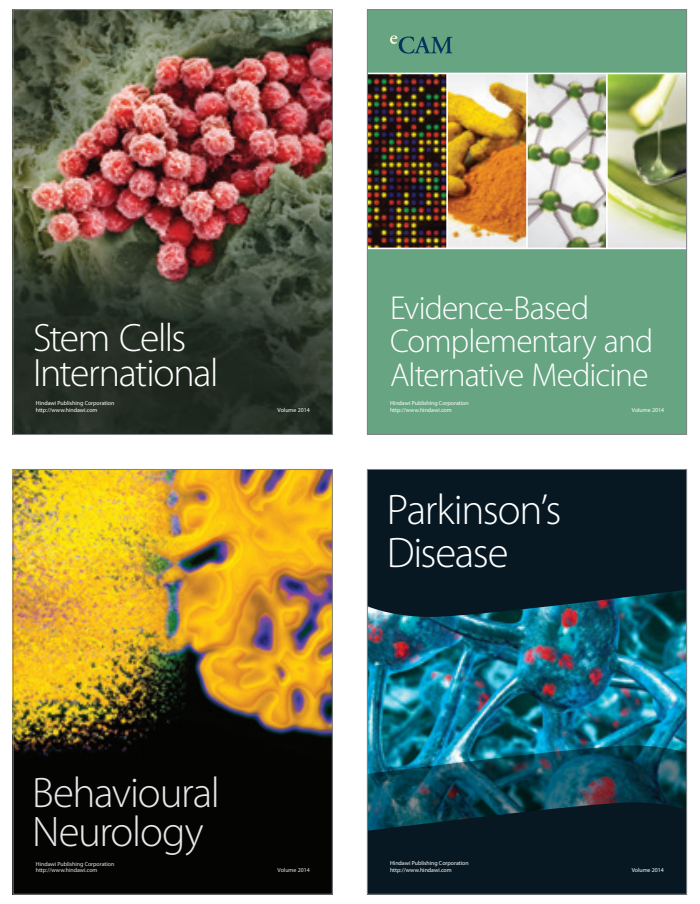
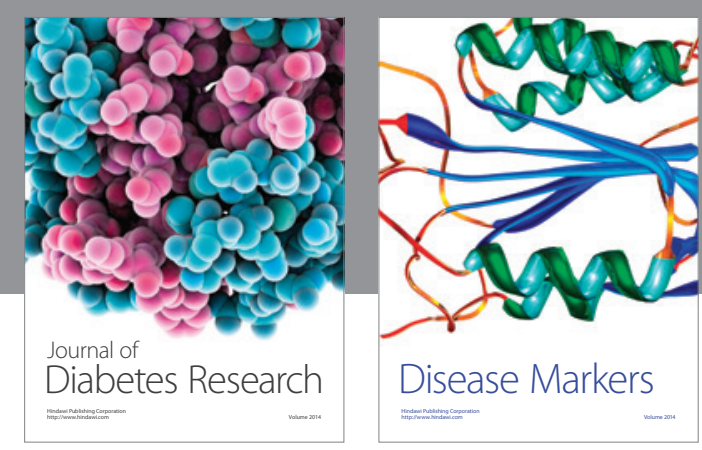

Disease Markers
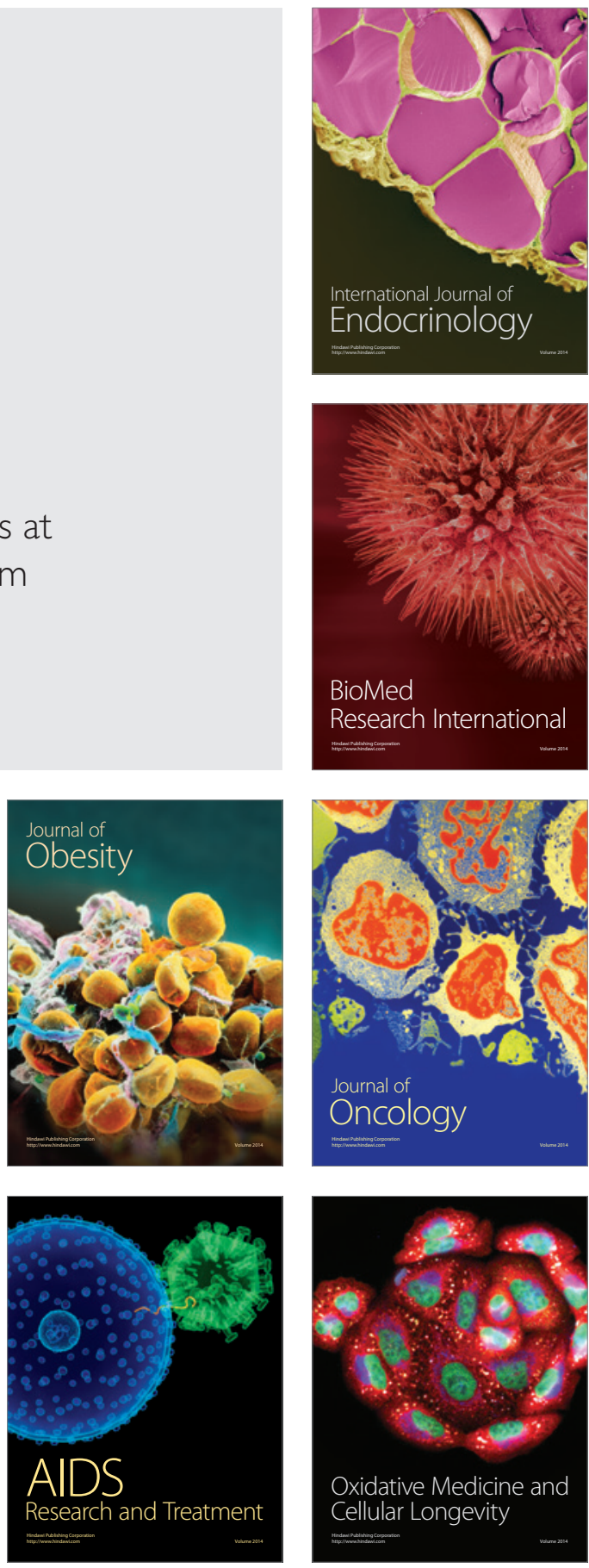